\title{
The Contemporary Value of Yunnan Cross-Border Ethnic Cultures in the B\&R Implementation
}

\author{
Ning Yan \\ International Business School \\ Yunnan University of Finance and Economics \\ Kunming, China \\ ningyan68@126.com
}

\author{
Mingyu $\mathrm{Xu}^{*}$ \\ Criminal Investigation School \\ Yunnan Police Officer Academy \\ Kunming, China \\ xmy1964@sina.com
}

\begin{abstract}
Located in the southwest of China, Yunnan has unique geological and cultural advantages. After an illustration of cultural identity of Yunnan cross-border ethnic groups, the paper explores the historical value of their cultures in securing national unity and promoting rapport with surrounding countries and then demonstrates the contemporary value of the cultures in the $B \& R$ implementation. The study recommends that Yunnan should realize the value and bring it into full play in enhancing and expanding cultural communication and exchanges to strengthen people-to-people bonds by means of educational cooperation in order to make a special contribution to the $\mathbf{B} \& \mathbf{R}$ implementation.
\end{abstract}

Keywords-Yunnan cross-border ethnic cultures; contemporary value; B\&R implementation

\section{INTRODUCTION}

The Vision and Action to Promote Jointly Building Silk Road Economic Belt and 21st Century Maritime Silk Road issued by China in 2015, which opens the prelude of the B\&R implementation, points out that the $B \& R$ is a systematic project, which should be jointly built through consultation to meet the interests of all, and efforts should be made to integrate the development strategies of the countries along the Belt and Road... We should respect different development paths and models chosen by different countries, support dialogues among different civilizations on the principles of seeking common ground while shelving differences, and drawing on each other's strength so that all countries can coexist in peace for common prosperity...We should enhance people-to-people and cultural exchanges, and mutual learning among the peoples of the relevant countries, and enable them to understand, trust and respect each other and live in harmony, peace and prosperity [1].

The statement has given priority to the function of culture in the $B \& R$ implementation, which is interpreted as a comprehensive view involving not only the economic and trade cooperation, but also the blending of diversified cultures from different countries [2]. Located in the southwest of China, Yunnan, with its unique geopolitical advantages and cultural features, plays and will certainly play an irreplaceable role in the $B \& R$ implementation to effectively promote the flow of peoples, cultural exchanges and economic and trade cooperation with neighboring countries.

The strategic status and mission of Yunnan in the B\&R implementation is described by the country as taking advantage of its regional advantages, promoting the construction of international transport channels connecting the surrounding countries, building a new highland of the Greater Mekong Sub-regional Economic Cooperation and developing into a radiation center open to the South and Southeast Asia [3] Yunnan borders with Vietnam, Laos and Myanmar and connects five countries including Thailand and Cambodia by Lancang-Mekong River. The 4060 kilometers long borderline of Yunnan, which accounts for about one fifth of the country's land borderline, connects 26 border counties of 8 border prefectures/cities in the province with 32 counties/cities/towns of 6 provinces of the 3 neighboring countries. There are now 16 first-class national ports, 7 second-class national ports, more than 90 border-crossing channels and more than 100 border markets in Yunnan. Meanwhile, Yunnan boasts most ethnic groups in China. Among its 25 ethnic groups, 16 groups live across the borderline sharing similar religions, languages and customs with the people live on the other side along the border.

Hence, starting with the demonstration of the geopolitical advantages of Yunnan and taking as the background the positive role of its ethnic cultures in the promotion of national unity, frontier's security and rapport with surrounding countries through the long process of governments' and peoples' communication and interaction, the paper focuses on the exposition of the cultural identity shared by cross-border ethnic groups and the exploration of contemporary value of the cultures in the B\&R implementation. The paper then makes recommendations that Yunnan should fully realize the contemporary value of its unique cultures and consequently tap the advantages of them in the $\mathrm{B} \& \mathrm{R}$ implementation through more higher-level and broader cultural and educational exchanges between Yunnan and neighboring countries so as to get involved and serve the B\&R implementation more actively and effectively. 


\section{LITERATURE REVIEW}

Since 2013 when China proposed the B\&R Initiative, the related studies have covered almost all the academic fields. Researchers, taking macro and micro perspectives, discuss diversified topics such as the political connotation of the $B \& R$, orientation of economic development, legal and institutional guarantee or cultural exchanges and security in the multidimensional background of politics, economics and culture and have achieved fruitful achievements, which has provided valuable policy recommendations and academic evidence to the sustainable development of the $B \& R$. Academic researches about Yunnan's position in the B\&R implementation could be classified into economic and cultural categories.

For instance, the researchers, taking economic perspective, discuss the topics such as how Yunnan should re-examine its strategic positioning in the $B \& R$, how Yunnan should seize the opportunity of the $B \& R$, give full play to its regional advantages and actively take part in the construction and development of BCIM economic corridor, the ASEAN Free Trade Area, and GMS, how the economic cooperation should be developed further between Yunnan and its neighboring countries as well as what development dilemma, opportunities and challenges encountered by Yunnan border trade.

And the researchers, taking the cultural perspective, discuss the topics such as how to promote and enhance the exchange and dissemination of its ethnic cultures, how to develop ethnic education and protect cultural security and how to facilitate social harmony and prosperity of ethnic regions in the background of the $\mathrm{B} \& \mathrm{R}$.

Hao states that one of the most important fulcrums of the $\mathrm{B} \& \mathrm{R}$ implementation is people-to-people bond and the most effective way to strengthen people-to-people bond is communication between cultures[4]. Liu, $\mathrm{Lu}$ and $\mathrm{Gu}$ emphasize that Yunnan, as the only province which could guarantee the security of land frontiers and ocean frontiers of the country at the same time, has been playing an important role to strengthen national and ethnic identity, maintain social stability and national unity [5][6][7]. Li and $\mathrm{Mu}$ comment that the B\&R implementation will greatly improve people's living standard along the route, and further promote economic \& trade exchanges and cooperation between surrounding countries with the result that the flow of peoples, cultural interaction and economic exchanges among nations will be more frequent [8][9].

Zheng and Huang believe that culture, as a spiritual bond linking all strategic partners, has a flexible affinity and strong penetration. The construction of destiny community in the $\mathrm{B} \& \mathrm{R}$ asks for the lubrication and impetus of culture [10][11]. Zhang observes that in the long-term economic and cultural exchanges, some cross-border ethnic villages located on the Yunnan-Myanmar borderline have built symbiotic communities with peoples from the other side of the border, which has transcended countries and nationalities and is becoming a vivid case of the regional community of common destiny [12].

The literature review shows that the strategic position of Yunnan in the B\&R implementation due to its unique geographical advantage and cultural characteristics has become more prominent, and Yunnan is being built as an radiation center towards South \& Southeast Asia with the support of preferential policies, financial aid and cultural funds from the country.

However, it is found that related researches still hold the stereotype that Yunnan is a relatively under-developed border province in southwestern China. As a result, the researchers try every means to make recommendations for the local government to push Yunnan to seize the historical opportunities and make effort to achieve leapfrog development in all aspects of society and economy, and finally change its image of being poor and backward. Indeed, some researches have been aware of the intermediary and lubricant role of Yunnan's unique ethnic cultures in the B\&R implementation, but more concerns are placed on how to protect, promote and inherit ethnic cultures while little is on the strong drive of the cultural advantages in the long history of building up good relationships with neighboring countries and its irreplaceable and brand-new value and relevant problem-solving approaches in the B\&R implementation.

Therefore, this research topic will be not only an important supplement to the previous academic researches, but also an valuable reference for the local government when planning, modifying and implementing the schemes or projects as to how to actively and effectively get involved in and serve the B\&R implementation.

\section{IDENTITY AND VALUE OF YUNNAN CROSS-BORDER ETHNIC CULTURES}

It is generally acknowledged by researchers that the cross-border ethnic group is a nation or a group sharing same culture but belongs to different countries. It could be aboriginal or migrating people who live along or near the borderline connecting two countries. The people classified as the same cross-border ethnic group should bear the same or similar cultural identity of origin, language and cultural characteristics [13][14][15].

TABLE I. YUNNAN BORDERING WITH NEIGHBORING COUNTRIES

\begin{tabular}{|c|c|c|}
\hline Yunnan-Vietnam & Yunnan-Laos & Yunnan-Myanmar \\
\hline Honghe Hani \& Yi & Pu'er City: 1 county & Xishuangbanna Dai \\
\hline Autonomous & & Autonomous Prefecture: \\
\hline Prefecture: 3 counties & & 3 counties \\
\hline Wenshan Zhuang \& & & Dehong Dai \& Jingpo \\
\hline Miao Autonomous & & Autonomous Prefecture: \\
\hline \multirow[t]{8}{*}{ Prefecture: 3 counties } & & 4 counties \\
\hline & & $\begin{array}{c}\text { Nujiang Lisu } \\
\text { Autonomous Prefecture: } \\
3 \text { counties }\end{array}$ \\
\hline & & Pu'er City: 3 counties \\
\hline & Notes: Jiangcheng & Baoshan City: \\
\hline & County of Pu'er City & 2 counties \\
\hline & borders with & \\
\hline & Myanmar and & Lincang City: \\
\hline & Vietnam. & 3 counties \\
\hline
\end{tabular}

Data Source: collected and compiled by the author 
TABLE II. DistrIBUtion OF 16 YunNAN CROSS-BORDER ETHNIC GROUPS

\begin{tabular}{|c|c|c|c|}
\hline $\begin{array}{c}\text { Yunnan- } \\
\text { Vietnam }\end{array}$ & Yunnan-Laos & $\begin{array}{c}\text { Yunnan- } \\
\text { Myanmar }\end{array}$ & $\begin{array}{c}\text { Yunnan- } \\
\text { Thailand }\end{array}$ \\
\hline Miao, Yao, & Miao, Yao, Yi, & Miao, Hani, & Miao, Hani, \\
Yi, Hani, & Hani, Lahu,Wa, & Jingpo, Lisu, & Lisu, Lahu, \\
Lahu, Dai, & Bulang, Dai & lahu, Wa, & Wa, Dai \\
Zhuang, & & De'ang, Nu, & \\
Buyi & & Dulong,Bulang & \\
& & Dai & \\
\hline
\end{tabular}

Data Source: collected and compiled by the author

\section{A. Group Origin}

A cross-border ethnic group inhabited on either side of the borderline of Yunnan has a common origin, similar culture and national psychology. Although affected by different political, social and economic environment of different countries, people belonging to same ethnic group have always retained the essence of its tradition in the long river of history [16].

For example, (1) In Vietnam, Dai and Nong are closely related to Zhuang in China; Miao and Yao migrated from Yunnan, Guangdong, Guangxi and Guizhou in the Ming Dynasty; Luoluo is closely related to $\mathrm{Yi}$ in China, and its language and customs are similar to that of $\mathrm{Yi}$ in China. (2) In Laos, Miao is the third largest ethnic group. Tai and Le were Dai habitated in Mengla County of Yunnan and migrated to Laos by way of Vietnam in the late Song Dynasty; Sandao inhabited in Luang Namtha and Po Qiao is Bulang in China. (3) In Myanmar, Shan is the second largest ethnic group with the same customs as that of Dai in China. Gao who is self-called "Aka" is Hani in China; Kachin is called Jingpo in China; Benglong has the same origin with De'ang in China. (4) Thai (Dai), Wa, Miao, Yao, Hani, Lisu and Lahu in Thailand have the same origins with some ethnic groups in Yunnan although Thailand doesn't border with Yunnan. Among them, Tai (Dai) is the main group in Thailand, who observes Theravada Buddhism which is the same with the religion of Dai in Yunnan.

\section{B. Language}

According to the linguistic classification, the languages used by Yunnan's cross-border ethnic groups belong to four language families.

TABLE III. LANGUAGE FAMILIES AND LANGUAGE USE OF CROSS-BordER ETHNIC GROUPS

\begin{tabular}{|c|c|c|c|c|c|}
\hline $\begin{array}{c}\text { Language } \\
\text { Family } \\
\text { Language } \\
\text { Use } \\
\text { Country }\end{array}$ & Yunnan & Myanmar & Laos & $\begin{array}{l}\text { Vietna } \\
\mathrm{m}\end{array}$ & $\begin{array}{l}\text { Thailan } \\
\text { d }\end{array}$ \\
\hline Tibeto-Burman & $\begin{array}{l}\text { Yi } \\
\text { Hani } \\
\text { Lahu } \\
\text { Lisu } \\
\text { Jingpo } \\
\text { Achang } \\
\text { Nu } \\
\text { Dulong }\end{array}$ & $\begin{array}{l}\text { Aka } \\
\text { Mexie } \\
\text { Lisu } \\
\text { Kachin } \\
\text { Maida } \\
\text { Nu } \\
\text { Dulong }\end{array}$ & $\begin{array}{l}\text { Luo- } \\
\text { luo } \\
\text { Ka- } \\
\text { guo } \\
\text { Lahu }\end{array}$ & $\begin{array}{l}\text { Luoluo } \\
\text { Hani } \\
\text { Kucho } \\
\text { ng }\end{array}$ & $\begin{array}{l}\text { Aka } \\
\text { Lahu } \\
\text { Lisu }\end{array}$ \\
\hline Zhuang-Dong & $\begin{array}{l}\text { Zhuang } \\
\text { Dai } \\
\text { Buyi }\end{array}$ & Dai & $\begin{array}{l}\text { Lao, } \\
\text { Dai }\end{array}$ & $\begin{array}{l}\text { Dai, } \\
\text { Nong } \\
\text { Dai } \\
\text { Buyi }\end{array}$ & Tai \\
\hline
\end{tabular}

\begin{tabular}{|l|l|l|l|l|l|}
\hline Miao-Yao & $\begin{array}{l}\text { Miao } \\
\text { Yao }\end{array}$ & $\begin{array}{l}\text { Miao } \\
\text { Yao }\end{array}$ & $\begin{array}{l}\text { Miao } \\
\text { Yao }\end{array}$ & $\begin{array}{l}\text { Hemen } \\
\text { Yao }\end{array}$ & $\begin{array}{l}\text { Miao } \\
\text { Yao }\end{array}$ \\
\hline Mon-Khmer & $\begin{array}{l}\text { Wa } \\
\text { De'ang } \\
\text { Bulang }\end{array}$ & $\begin{array}{l}\text { Wa } \\
\text { Benglong }\end{array}$ & $\begin{array}{l}\text { Lawa } \\
\text { Bula } \\
\text { ng }\end{array}$ & & \\
\hline \multicolumn{5}{|c|}{ Data Source: Liu [17] and He[18] }
\end{tabular}

\section{Religion}

Religion is a unique cultural phenomenon that has emerged with the beginning of history and has been playing an extremely important role in linking the people holding the same belief [19]. It is not an uncommon phenomenon that the cross-border ethnic groups with same or relative origins believe in the same religion although they live on different sides of the borderline and belong to different countries. For example, Theravada Buddhism is introduced from Myanmar and Dai in Yunnan, Shan in Myanmar, Thai (Le) in Laos and Vietnam, and Le in Thailand who believe in Theravada Buddhism are of the same origin.

\section{Customs}

Customs, which have been formed in long history and inherited from generation to generation, are an important cultural symbol representing the practitioners' thought, behavior and language. The similarities of customs practiced by Yunnan cross-border ethnic peoples have been a key drive to strengthen the sense of affinity and the awareness of identity among the peoples and promote the communication between the peoples. For example, Zhao observed that Jingpo people of Yingjiang County, Dehong Prefecture, Yunnan, invited Jingpo people from the other side of the border to celebrate the grand traditional festival $\mathrm{Mu} \mathrm{Nao}$ Zong Ge. When Kachin people in Myanmar held important ceremonies, they would send for the prestigious "Zawa" to go to the other side of the borderline to tell and sing epics [20]. Water Splashing Festival is the grandest traditional festival observed by Dai, De'ang and Achang. During the carnival, cross-border ethnic peoples in Yunnan and Myanmar will gather together to worship the Buddha, visit each other, sing and dance. In Jiangcheng County of Yunnan, which borders with Laos and Vietnam, inhabited by 9 cross-border ethnic groups, the government ever held a traditional Sports Festival called Duibao and invited Laos and Vietnam delegations to attend the festival [21][22].

In fact, there is no other country in the world like China which has a long history of friendship with all the countries in Southeast Asia. In geography, race, culture and many other aspects, China has a affinity with those countries [23]. According to the relevant data, the cultural communication, exchanges and cohesion between China and Southeast Asian cross-border ethnic groups are of a long history and boast solid basis [24].

The distinct cultural identity of Yunnan's cross-border ethnic groups plays a special and important role in strengthening ethnic unity and improving economic and social communication and cooperation in the border areas. An Laos researcher, Thipmuntali shows that if we view the Mekong River running through Laos, Myanmar, Thailand, Vietnam and China from a cultural rather than a geographical perspective, we will surely find that the peoples and the governments in this region have a well-established relationship with one another and the Mekong River is not a dividing line, but a shared lifeline within these countries [25].

Once the cultural identity is formed, it has strong stability, cohesiveness and affinity, and will not be restricted by geographical environment, language, economic models and social life [26]. From the above analysis, there will be no doubt that Yunnan unique and rich resources of cross-border ethnic 
cultures are of great contemporary value and significance in the B\&R implementation, which has identified people-to-people bonds as a core element to its success.

\section{OPtIMIZING CROSS-BORDER CULTURAL EXCHANGE PLATFORMS AND PROVIDING PERSONNEL SUPPORT TO THE B\&R IMPLEMENTATION}

Since 2013 when B\&R Initiative was proposed for the first time, flow of peoples, cultural exchange and economic interaction among the countries along the route have been accelerated a lot owing to the more effective mutual learning between different civilizations and peoples. On the basis of fully understanding the contemporary value of Yunnan cross-border ethnic cultures in the $\mathrm{B} \& \mathrm{R}$ implementation, it is necessary for the province to excavate and bring into full play of the cultural advantages to promote and enhance communication and interaction among peoples in neighbouring countries. To begin with, we should respect and protect the cultural tradition, identity and ecology developed by cross-border ethnic groups over the years, and then face with the difficulties and obstacles encountered in the development, make deeper exploration of cultural resources with innovative spirits and optimize the cultural exchange platforms and mechanism.

The Notice of Jointly Building the B\&R Education Action issued by the Ministry of Education (hereafter MoE) points out that education is a base for national prosperity, ethnic unity and happiness of the people and plays a leading role in the B\&R implementation. The Notice requires all localities take advantages of their own geographical and cultural characteristics, highlight the initiative of local government in contributing to the B\&R implementation, formulate local action plans for education going out of the country based on the country's overall strategy [27].

Education, as a key vehicle of culture, should take the lead to serve the $B \& R$ implementation. As the starting point of school education, the elementary education of cross-border ethnic regions in Yunnan has gone through a process of making a trial, opening up and model formulating. In the 1980s, the regulations on the border areas of China-Laos and China-Myanmar became looser to meet the needs of the political and economic development of the countries.

The border areas were gradually opening up to make it possible for the children to study in schools on either side of the borderline. In the early 1990s, with the country's reform and opening up policies, the flow of human resources with migrant workers as its main component in the border areas increased dramatically and the number of migrant children going to other countries to receive elementary education increased as well. In the late 1990s, there appeared a phenomenon that children living on Yunnan side went to neighboring countries to receive elementary education because the neighboring countries such as Vietnam, Laos and Myanmar gave special political and financial priority to the elementary schools located on their northern border areas.

Those changes has aroused the attention of Yunnan provincial government. Since 2000, the government adjusted the educational development plan, took the lead in practicing the "Three Free" (excluding for textbook fees, miscellaneous fees and stationery fees) compulsory education for students in poor villages along the borderline. The action has brought more and more children ever studying abroad back to home schools, and more overseas students to come to study in schools in Yunnan.

Along with the distinct improvement of mutual sharing of cross-border elementary education resources, cross-border higher education, with the strategic plan on the cultivation of international professionals, has become an important way to promote people-to-people bonds in the $\mathrm{B} \& \mathrm{R}$ implementation. According to the Notice issued by MoE [28], the current cooperation of cross-border higher education should focus on promoting the common aspiration of the peoples and carry out a wider and higher-level of cultural exchanges to provide personnel support to the $\mathrm{B} \& \mathrm{R}$ implementation. Higher education should serve the countries along the route to achieve policy coordination, facilities connectivity, unimpeded trade, financial integration and people-to-people bonds.

The cross-border higher education in Yunnan could be traced back to the late Qing Dynasty and the Republic of China. In the 21st Century, with more frequent cultural exchanges between Yunnan and South \& Southeast Asian countries, many colleges and universities in Yunnan have been running cross-border educational cooperation projects with the central and South Peninsula countries.

According to the requirements by the Curriculum internationalization Reform, however, cross-border higher education in Yunnan has large room to be improved. For example, the number and quality of bilingual academic courses, intercultural communication courses and exchange of teachers and students are in need of being updated and increased. Besides, teachers, teaching materials and teaching methods of universities in Yunnan are far beyond the requirement of curriculum internationalization. These development bottlenecks have hindered the coordinated development of cross-border higher education in the new era [29].

In view of the current situation and existing problems of cross-border education in Yunnan, schools at all levels, including elementary education, secondary or vocational education and higher education should expand cooperation and exchanges between countries along the route. High-quality educational resources of the countries should be integrated to go out and and the high-quality resources from other countries should be introduced with the international vision of openness and inclusiveness, mutual learning and mutual benefit. Higher education should be based on its own development orientation and regional strategy to carry out various forms of cooperation and cooperation with countries along the route, innovate personnel training modes, enhance the quality of international students, and optimize co-operational platforms. Non-governmental organizations should be encouraged to follow the trend and carry out broader, deeper and higher-level educational cooperation and exchange and devote themselves to the opening up and reform of education to provide professionals to serve the B\&R implementation.

\section{CONCLUSION}

Sixty-five countries are located along the Belt and Road, with a population of around 3 billion on Silk Road Economic Belt. The region is full of huge development potential and a big trade capacity. However, the mission of making the gorgeous blueprint of the B \& R into reality cannot be carried out by one country or one nation. It calls for more extensive and higher-level exchanges and cooperation among countries along the route in infrastructure construction, trade and investment, industrial cooperation and other economic aspects, which embraces people-to-people bond as the decisive element. That is, better and wider understanding and communication by means of cultural exchange, joint talent cultivation, and other humane aspects are the contributing factors to the success of the B\&R implement.

Yunnan, a typical province with outstanding geographical and cultural advantages in Southwest China, has developed a well-established ecological system integrating mountain, fishery and irrigation agriculture civilizations with the effort 
made by neighboring countries in terms of people flow, migration, intermarriage and mutual market in border areas. Meanwhile, Yunnan has developed a multicultural system blending Chinese culture, Indian culture, Islamic culture and Western culture in terms of cultural exchanges, communication and adaptation between Yunnan and South \& Southeast Asian countries. This special cultural and geographical community connected by mountains, rivers and peoples will play an indispensable role in the $R \& B$ implementation. Yunnan should recognize the contemporary value of its own cultural advantages, in the face of problems and difficulties in the process of development, gather together social efforts from all sectors and fields, fully tap its development potential and make a special contribution to the B \& R implementation.

\section{REFERENCES}

[1] State Development and Reform Commission, Ministry of foreign affairs and Ministry of Commerce, "The vision and action to promote the implementation of the Silk Road Economic Belt and the Maritime Silk Road in 21st century," [EB/0L]. 2015-03-28.

[2] S.Y. Hao, "Cultural diversity and B\&R," Guangming Daily, 2015-05-28:11.

[3] Z. Liu "The types, attributes and development trends of cross-border ethnic groups," Yunnan Social Science, No.5, 2004, pp. 89-93.

[4] M,G.Lu, "Study on border Education security under the background of B\&R,” Dissertation, Yunnan Normal University, 2016.

[5] Y.H.Gu, N.Wu, and W.F.Gu, "Cultural security and bilingual education of cross-border ethnic groups in Yunnan under the Background of the B\&R Initiative," Journal of Research on Education for Ethnic Minorities, No.5, Vol. 28, 2017, pp. 5-9.

[6] Z.H. Li, "The ethnic corridor and ethnic relationship in the context of the B\&R," Guizhou Ethnic Studies, Vol. 1, 2016, pp.73-76.

[7] H.X.Mu, "Study on the protection and development of ethnic groups' cultures under the B\&R," Journal of South-Central University for Nationalities, No.4, 2017, pp. 69-72.

[8] S.P. Zheng, "Construction of cultural exchange mechanism in the B\&R," Academic Exchange, No.12, 2015, pp. 112-117

[9] W.S.Huang, "A Study on the role of Yunnan's ethnic cultural characteristics in the strategy of the B\&R," Value Engineering, No.9, 2017, pp. 1-5

[10] H. Zhang and J.Liu, "Transnational symbiotic community construction under the background of the B\&R," Journal of Northwest Minzu University, No.3, 2017, pp. 7-13

[11] Z. Liu and X. Shen, "A study on the cross-border ethnic groups in Yunnan," Yunnan Social Science, No.1, 1989, pp. 89-93.

[12] J.X. Zhou, "The cross-border ethnic groups and their relationships over China-Vietnam and China-Laos," Beijing: Nationalities Publishing House, 2002.

[13] T. Fang, "Distribution, origin and characteristics of cross-border ethnic groups in Yunnan," Journal of Guangxi University for Nationalities, Vol.29, No.5, 2007, pp. 9-20.

[14] T.G. Zhao, "A study of the cross-border ethnic groups in Yunnan," Kunming: Yunnan National Publishing House, 1998.

[15] Z. Liu and X. Shen, "A study on the cross-border ethnic groups in Yunnan," Yunnan Social Science, Vol. 1, 1989, pp.76-83.

[16] S.Y. He and C. Li, "The strategy for building Yunnan into a gateway in China's opening up to the southeast Asia and the development of the of the cross-border ethnic cultures in Yunnan," Journal of Yunnan Nationalities University, Vol. 5, 2011, pp. 221-228.

[17] S. J. Fang and Z. H. Lv, "Religious belief and China's border land management," Journal of Yunnan Minzu University, No.1, 2014, pp. 5-12.

[18] J. Zhao, "Cross-border ethnic literature and cross-border ethnic peoples, their history, reality and future," Studies of Ethnic Literature, Vol. 3, 1987, pp. 28-32.

[19] J.H. Dong, "Cross-border exchange of ethnic traditional sports," Journal of Yuxi Normal University, Vol.29, No.3, 2013, pp. 66-68.

[20] L.C. Pu, "Cultural exchanges and safety of Yunnan cross-border ethnic groups in the Implementation of the Gateway Strategy," Journal of Yunnan Nationalities University, Vol.30, No.2, 2013, pp. 12-16.

[21] X. J. Chen, "Collection of ancient history studies in Southeast Asia by Chen Xujing," Hong Kong Commercial Press, 1992, p.5.
[22] K. Thipmuntali, "The Lue of Muang Sing," in Laos, culture and society, G, Evans Ed. Chiang Mai: Silkworm Books, 1999, p. 150.

[23] Ministry of Education of China, "The notice of pushing to co-build B\&R education action,' http://www.moe.gov.cn/srcsite/A20/s7068/201608/t20160811_274679.h tml

[24] Y.H. Fu, "Exploring educational methods of ethnic groups in Yunnan in the boundary areas from perspective of synergy development," Journal of Qujing Normal University, Vol.32, No.3, 2013, pp. 97-101. 